\title{
Impact of the Heat Transfer on the Performance Calculations of Automotive Turbocharger Compressor
}

\author{
P. Chesse*, D. Chalet and X. Tauzia \\ Laboratoire de Mécanique des Fluides, UMR 6598 CNRS, Équipe Énergétique des Moteurs à Combustion Interne, École Centrale de Nantes, \\ BP 92101, 44321 Nantes Cedex 3 - France \\ e-mail: pascal.chesse@ec-nantes.fr - david.chalet@ec-nantes.fr - xavier.tauzia@ec-nantes.fr \\ * Corresponding author
}

\begin{abstract}
Résumé - Influence des transferts thermiques sur le calcul des performances des compresseurs de suralimentation - En général, les turbocompresseurs pris en compte dans les logiciels de simulation moteur sont modélisés de façon adiabatique. Cependant, les tests expérimentaux effectués au laboratoire montrent que ce n'est pas toujours le cas. L'utilisation directe des champs de fonctionnement fournis par les constructeurs de turbomachines n'est alors plus possible. Une évaluation quantitative de ces transferts, basée sur des tests réalisés sur un banc d'essais turbo à air chaud, est présentée. Puis ils sont pris en compte afin de calculer les caractéristiques réelles de fonctionnement d'un compresseur. La différence avec le modèle adiabatique apparaît très importante pour les faibles puissances compresseur. Ceci correspond aux faibles charges moteur.
\end{abstract}

\footnotetext{
Abstract - Impact of the Heat Transfer on the Performance Calculations of Automotive Turbocharger Compressor - Usually, turbochargers used within internal combustion engine simulation software are modelled in an adiabatic manner. However, during our experimental tests we found that this is not necessarily the case. The direct use of the manufacturer's map is not possible anymore. A simple method which considers the heat transfers is proposed. It is based on experimental tests made on hot air supplied turbocharger test bench. The difference with the adiabatic model is considerable mainly for low compressor power. This corresponds to internal combustion engine low loads.
} 


\section{DEFINITIONS, ACRONYMS, ABBREVIATIONS}

$\dot{m} \quad$ Mass flow $(\mathrm{kg} / \mathrm{s})$

$Q \quad$ Heat flux (W)

Cp Specific heat at constant pressure (J/( $\mathrm{kg} . \mathrm{K}))$

$\Delta h \quad$ Total mass enthalpy difference $(\mathrm{J} / \mathrm{kg})$

$s \quad$ Entropy $(\mathrm{J} /(\mathrm{kg} . \mathrm{K}))$

$P \quad$ Stagnation pressure $(\mathrm{Pa})$

$T \quad$ Stagnation temperature $(\mathrm{K})$

$P_{\text {comp }} \quad$ Compressor mechanical power (W)

\section{Greek letters}

$\eta \quad$ Efficiency

$\gamma$ Specific heat ratio

$\tau$ Compression ratio

\section{Subscripts}

1 Inlet

2 Outlet

is Isentropic

c Compressor

$t$ Turbine

man Manufacturer map

adia Adiabatic

\section{INTRODUCTION}

The internal combustion engine adjustment relies more and more on whole engine1-D simulation code. With this sort of simulator it is possible to consider the interactions between the different engine parts and to predict the general engine behaviour. Amongst the best known are GT-Power [1], Boost [2], Wave [3] or AMESim [4]. The turbocharging system is described in a simple way. The compressor and the turbine are considered as adiabatic. This type of code uses directly the turbocharger maps, usually provided by the manufacturers, to deduce the turbocharger operating point as below.

The simulator produces the following input data:

- inlet and outlet compressor pressures;

- inlet and outlet turbine pressures;

- inlet compressor and turbine temperatures;

- turbocharger rotation speed.

The turbocharger model should calculate the following parameters:

- turbine and compressor power;

- turbine and compressor mass flow rates;

- compressor and turbine outlet temperatures.
These parameters allow continuing the simulation. The compressor characteristics are presented on a (compression ratio/mass flow rate) map including efficiency and rotation speed curves. It is possible to locate the operating point from the compression ratio and the rotation speed. The efficiency $\eta_{c}$ and mass flow rate $\dot{m}_{c}$ are then determined. The outlet compressor temperature $T_{c 2}$ is then calculated using adiabatic hypothesis.

$$
T_{c 2}=T_{c 1}\left(1+\frac{\left(\frac{P_{c 2}}{P_{c 1}}\right)^{\frac{\gamma-1}{\gamma}}-1}{\eta_{c}}\right)
$$

The compressor mechanical power $\dot{W}_{c}$ is then deduced from the first law of thermodynamic using adiabatic hypothesis and perfect gas law, assuming that $C p$ is constant:

$$
\dot{W}_{c}=\dot{m}_{c} C p_{c}\left(T_{c 2}-T_{c 1}\right)
$$

The manufacturer compressor map is developed from turbocharger test bench measurements. A fluid (engine exhaust gas or heated air) is expanded in the turbine to draw the compressor to the different rotation speeds tested. For each of this rotation speed, the compressor outlet is progressively closed to test the maximum mass flow rate range. The test stops when the surge line is reached. The inlet turbine gas temperature is often quite high to be closer to normal conditions on an engine. For this study's turbocharger the manufacturer used a gas temperature of $600^{\circ} \mathrm{C}$. For each operating point, the mass flow rate, the inlet and outlet pressures and temperatures of the compressor are measured. The adiabatic efficiency shown on the manufacturer compressor map $\eta_{c-\text { man }}$ is deduced from these measures:

$$
\eta_{c-\operatorname{man}}=\frac{T_{c 2-i s}-T_{c 1}}{T_{c 2}-T_{c 1}}
$$

$T_{c 2-i s}$ being the outlet temperature of an isentropic compressor for the same compression ratio:

$$
T_{c 2-i s}=T_{c 1}\left(\frac{P_{c 2}}{P_{c 1}}\right)^{\frac{\gamma-1}{\gamma}}
$$

If the compressor is not adiabatic, Equation (1) and (2) are not correct and Equation (3) doesn't correspond to the usual isentropic efficiency definition. So, this point should be verified.

\section{BIBLIOGRAPHY SURVEY}

One of the first studies of this phenomenon is Rautenberg's et al. [5] in 1983. These authors emphasise the heat transfer influence on the turbine power and on the compressor outlet temperature. The increase of this temperature leads to a density decrease, which isn't favourable to the engine volumetric 




Figure 1

Compression process model according to [9].

efficiency. The usual isentropic efficiency is wrongly used. It doesn't define the aerodynamical quality of the compression, because it considers the heat transfers between the turbine, the compressor and the surrounding area. Thanks to experimental tests, the authors note a strong dependence between turbine inlet temperature and compressor outlet temperature. The geometrical turbocharger characteristics, mainly the distance between compressor and turbine, appear to influence greatly the heat fluxes. More recently, in 2002, Jung et al. [6] suggest a parameterisation of turbine maps to obtain the behaviour of the turbine in its actual environment. They study heat losses considering the turbine as an exchanger which efficiency is derived from the manufacturers map. Aerodynamic and heat efficiencies are then added to obtain the global efficiency.

In 2003, Bohn et al. [7] present a computational and experimental study of the internal turbocharger heat transfers. A three-dimensional calculation is performed on the center housing, the compressor and the turbine. The boundary conditions were derived from experimental test data. The temperature surface of the casing is measured with thermography-camera and resistance thermometers. This includes the aerothermal boundary conditions for the fluid at the inlet and outlet of the compressor and turbine. The measurement techniques are detailed in [8]. For the compressor, the transfer direction seems to change along the flow mean line. This transfer occurs from the flow to the wall for the first impeller part, and then reverses for the second part. This reversing limit is dependant on the compressor flow. From numerical simulation, the authors propose a heat transfer correlation based on inlet compressor and turbine temperature, on compressor flow and on geometrical and material characteristics of the turbocharger. The rotation speed doesn't figure in this correlation. The conclusion of [9] is fairly similar. The compression process proposed by the authors is represented in Figure 1. The diabatic compression can be represented by a first heat transfer before the compression, then an adiabatic compression and a second heat transfer after the compression.

For slightly different turbomachinery, Riegler [10] suggests an alternative technique to consider heat transfer in gas turbine performance calculations based on lumped capacitance method. The main idea is to consider only heat transfer effects on the working fluid properties changes. The heat transfers are calculated thanks to correlations which express the dependency on the most relevant parameters describing the influence of fluid flows, and in addition on time in transient operation. With this method, the calculations for the temperatures of the structures are not necessary. Another available study is Guzovic's et al. [11]. They propose different Nusselt correlation for flow/wall heat transfer in turbomachinery.

Even so this different studies are few, they all advance that the heat transfers cannot be neglected, more so between the compressor and the turbine. The heat transfers must be considered to simulate correctly a turbocharger.

$0 \mathrm{D} / 1 \mathrm{D}$ engine simulators seem to fit well with experiments because they are often used to study operating conditions (typically high load/full load under steady state conditions) for which heat transfers through the turbocharger are negligible. For less favourable operating conditions (such as low load and/or transients) the results are less satisfactory, so that it is sometimes necessary to modify compressor and/or turbine maps to improve simulation fitting with experiments. A compressor map measured under the hood is very different from a manufacturer compressor map [12].

The combination of the compressor efficiency measurement methodology used by turbochargers manufacturers and the way compressor maps are traditionally used in engine simulation codes (apparent efficiency used as an isentropic efficiency) leads to underestimation of actual compressor efficiency. Thus, for a given mechanical power, boost pressure is underestimated as well.

For the turbine, the measurement methodology is often different: the turbocharger manufacturer evaluates the turbine efficiency from the apparent power absorbed by the compressor (which is not purely mechanical power, as shown by our study):

$$
\begin{aligned}
& \eta_{t-\text { man }}=\frac{P_{t u r b}}{P_{t u r b-i s}}=\frac{\frac{P_{c o m p}}{\eta_{\text {meca }}}}{P_{\text {turb-is }}} \\
& \eta_{\text {meca }} \times \eta_{\text {turb }}=\frac{P_{\text {comp }}}{P_{\text {turb-is }}}=\frac{D m_{\text {comp }} C p_{\text {comp }}\left(T_{S-\text { comp }}^{*}-T_{E-\text { comp }}^{*}\right)}{D m_{\text {turb }} C p_{\text {turb }} T_{E-t u r b}^{*}\left(1-\left(\frac{P_{S-t u r b}^{*}}{P_{E-t u r b}^{*}}\right)^{\frac{\gamma-1}{\gamma}}\right)(6)}
\end{aligned}
$$


Since the mechanical power absorbed by the compressor is over-estimated, the product $\eta_{\text {meca }} \times \eta_{\text {turb }}$ is also overestimated. If $\eta_{\text {turb }}$ is evaluated directly from the temperatures difference between turbine inlet and outlet, it is also overestimated because of heat transfer (experimentally efficiencies greater than one can be found!).

But the errors committed for turbine and compressor evaluation only compensate when the actual turbine inlet temperature is equal to the turbine inlet temperature used by the turbocharger manufacturer for maps measurements. If the actual turbine inlet temperature is lower, it is no longer the case.

In this paper, we propose an experimental method to determine compressor internal heat transfers in a turbocharger. The results obtained with this method are then used to compare compressor calculation with and without taking into account internal heat transfers.

\section{TEST BENCH AND TURBOCHARGER PRESENTATION}

The experimental facility is a steady flow turbocharger test bench located at the Fluids Mechanics Laboratory at École Centrale de Nantes (France) (see Fig. 2). It is based on a volumetric screw compressor as pressure generator and on two air heaters to obtain the wanted turbine inlet temperature. The screw compressor maximum pressure is 7 bars and the maximum air mass flow is $0.24 \mathrm{~kg} / \mathrm{s}$ in the normal conditions.
The compressed air is filtered and dried before entering the turbine inlet line. The air heaters allow the regulation of the turbine inlet temperature varying from $300 \mathrm{~K}$ to $950 \mathrm{~K}$. A valve at the turbine inlet controls the turbine expansion ratio and air mass flow. At the compressor outlet, a back pressure valve is used to control compression ratio and compressor air mass flow. Air is then exhausted outside by an extractor fan. In this way, the compressor is used as a brake to test the turbine. The turbine can also be used as a motor to test the compressor. A pressure regulator is added to the turbine inlet line to avoid pressure overshooting. The turbocharger test bench and the turbocharger are insulated to drastically reduce all heat transfers to the surrounding. An oil pump lubricates the turbocharger. A heater and cooler were used to regulate oil temperature. This turbocharger test bench allows to measure:

- turbine and compressor inlet and outlet temperatures;

- turbine and compressor inlet and outlet pressures;

- oil inlet and outlet pressures and temperatures; oil volumetric flow;

- turbocharger speed.

The different transducers used for the performance measurement are presented bellow:

- mass flow rate was measured by a thermal mass flow meter, a Proline t-mass 65F (see Fig. 3) (range 0.005$0.025 \mathrm{~kg} / \mathrm{s}$; accuracy: $\pm 1.5 \%$ );

- rotational speed was measured by means of an inductive sensor (see Fig. 4) (range 0-200 $000 \mathrm{tr} / \mathrm{min}$, accuracy $\pm 200 \mathrm{tr} / \mathrm{min}$ );

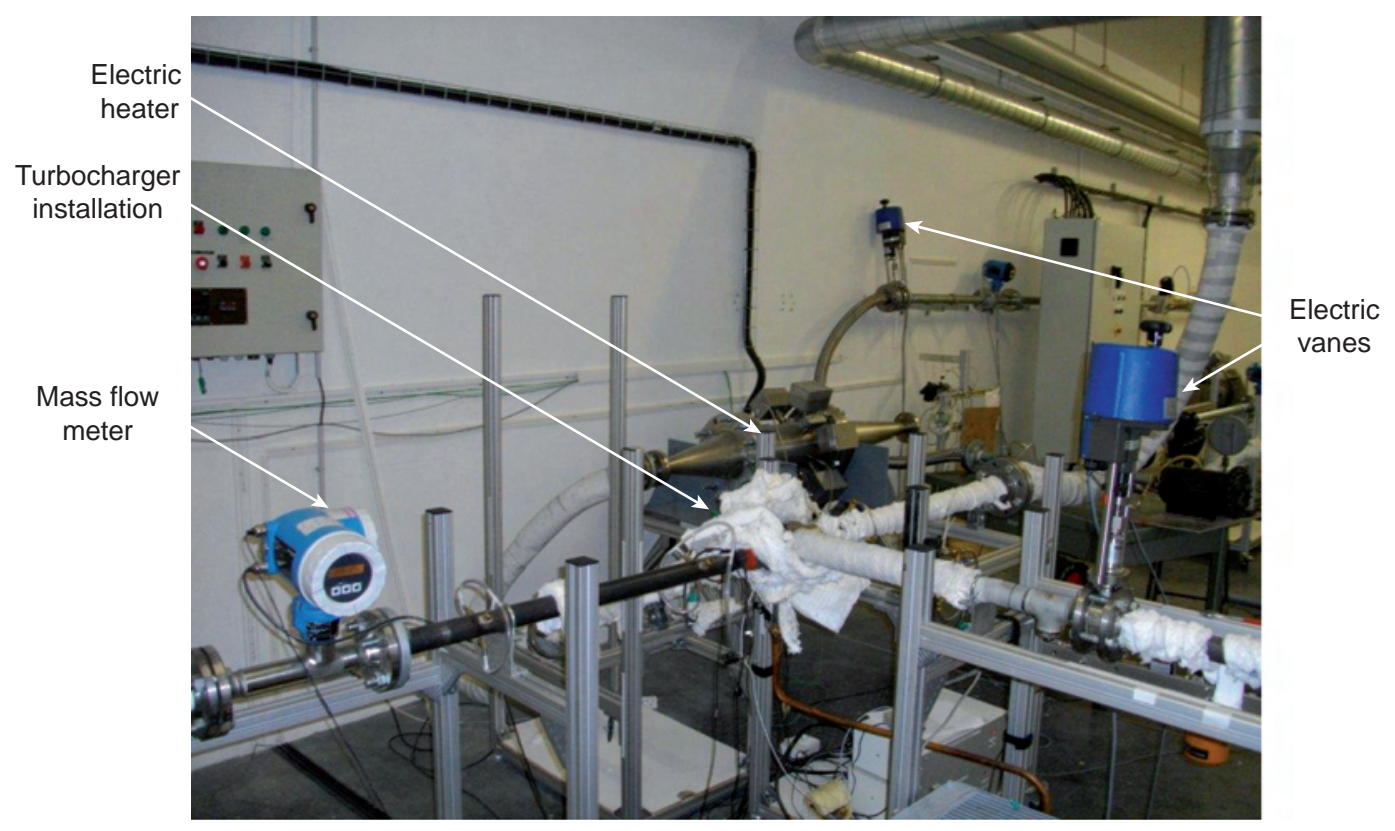

Figure 2

Overall turbocharger performance test facility. 
- temperature was measured using $\mathrm{K}$ type thermocouples located in the compressor entry and delivery lines, (range $0-1000^{\circ} \mathrm{C}$; accuracy $\pm 1^{\circ} \mathrm{C}$ ),

- piezoresistive sensors were installed to measure inlet and outlet static pressures (see Fig. 5).

All transducer signals are connected to a "NATIONAL INSTRUMENT" data acquisition Plug-in board in the measurement computer. A "LabView" based data acquisition system is used to measure, monitor and store all the available measurement signals (see Fig. 6).

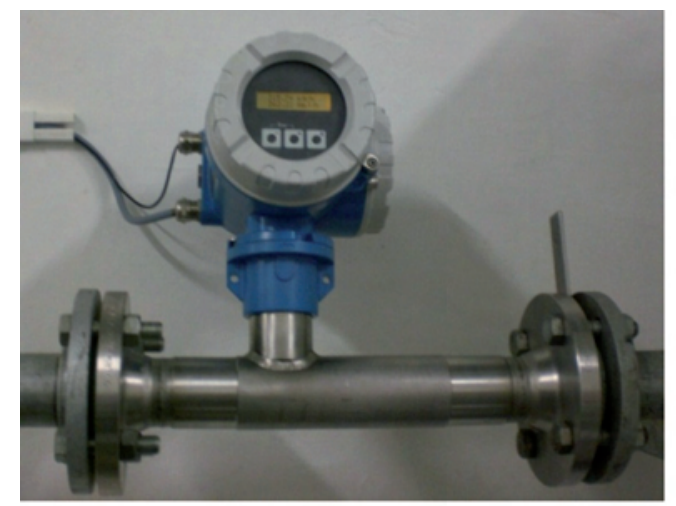

Figure 3

Thermal mass flow meter (Endress-Hauser).

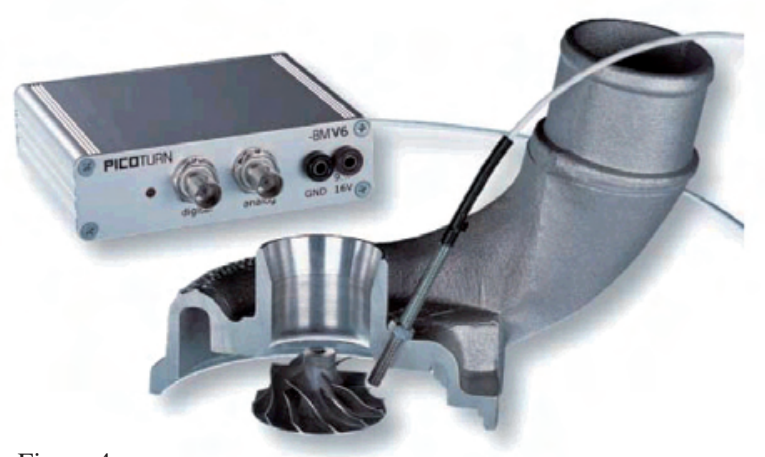

Figure 4

Inductive sensor for rotational speed measurement (PICOTURN).

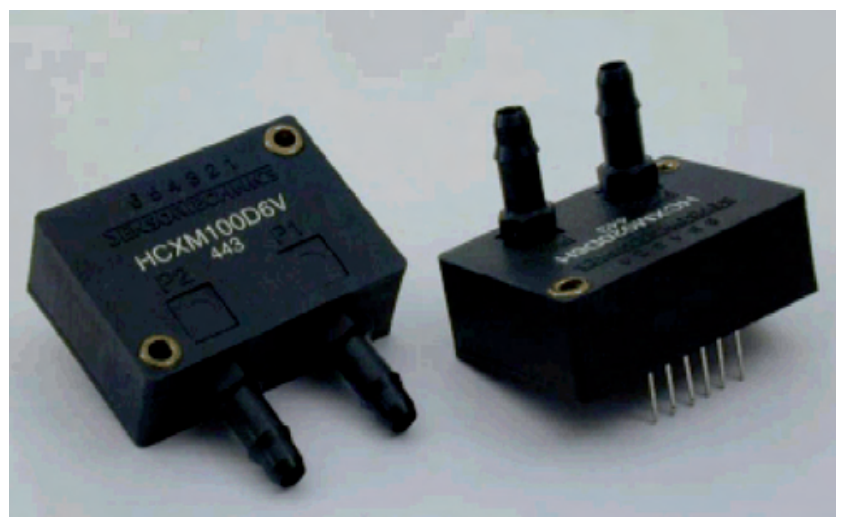

Figure 5

Piezoresistive sensors for static pressure measurement (SensorTechnics)

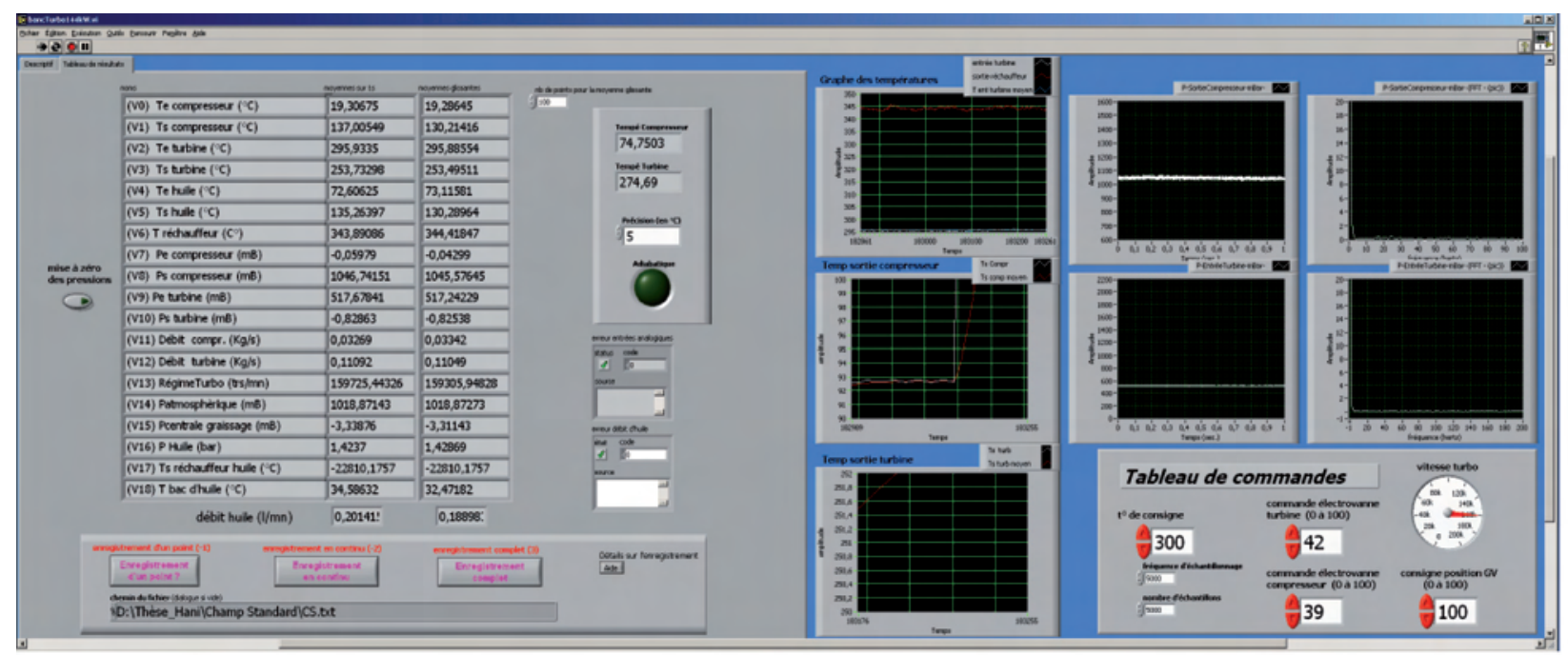

Figure 6

Used LabView, screenshot. 
Geometric and Aerodynamic Analysis Parameters of the Tested Compressor

The compressor is a part of a BorgWarner automotive variable geometry turbocharger used on a 1.51 engine. It employs a back swept impeller and 12 radial blades at exit: six of them are short splitters. The outlet impeller diameter is $46 \mathrm{~mm}$. The diffuser is vane-less with radial parallel plates.

\section{EXPERIMENTAL TESTS AND RESULTS}

The first step consisted in measuring the adiabatic compressor performances. For each operating point, the turbine inlet temperature has been adjusted to obtain an average turbine temperature equal to the average compressor temperature, where average temperature means arithmetic mean of inlet and outlet temperature of each element. Moreover, the turbocharger is isolated from the surround. This is done in order to minimize the internal and external heat transfers. It has been possible to obtain, in this way a real isentropic efficiency. The corresponding compressor map is shown in Figure 7. The $100000 \mathrm{rpm}$ iso-speed corresponds to $240.8 \mathrm{~m} / \mathrm{s}$ blade tip speed.

The next experimental test consisted in measuring several compressor maps with various turbine inlet temperatures, keeping isolation from the surround. Results are presented in Figure 8 and Figure 9 for $300^{\circ} \mathrm{C}$ and $500^{\circ} \mathrm{C}$ inlet turbine temperature.

An important difference between the 3 maps is the extension of the measured zone. The higher the turbine inlet temperature, the larger the measured zone is. Indeed, the turbine inlet pressure was limited to 3 bar(abs) to avoid any damage to the turbine. Thus the power delivered by the turbine is limited when turbine inlet temperature is low, as it is the case for the adiabatic test. A direct comparison between adiabatic map and map obtained with a $500^{\circ} \mathrm{C}$ inlet turbine temperature is shown in Figure 10.

First, it is noticeable that constant speed lines are not modified when the inlet turbine temperature changes. This seems that aerodynamic internal losses are not altered by this temperature change. This in turn seems to confirm that when a heat transfer happens, it is situated after the impeller. Indeed, if a heat transfer happened before the wheel, the velocities triangle would be modified and the aerodynamic losses would also be changed. In that case the constant speed lines would be altered, which is not observed experimentally.

However, the efficiency lines are very different from one map to the other, confirming the existence of significant heat transfer. The discrepancies between the two maps are larger for low mass flow and compression ratio.

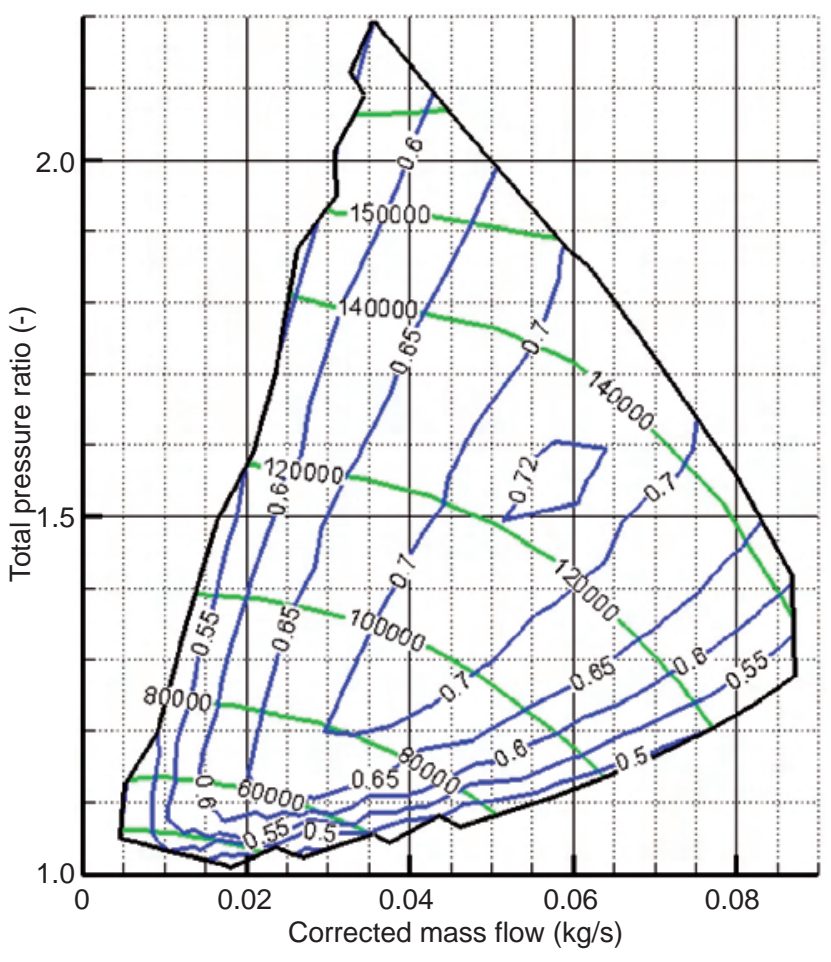

Figure 7

Adiabatic map of the compressor.

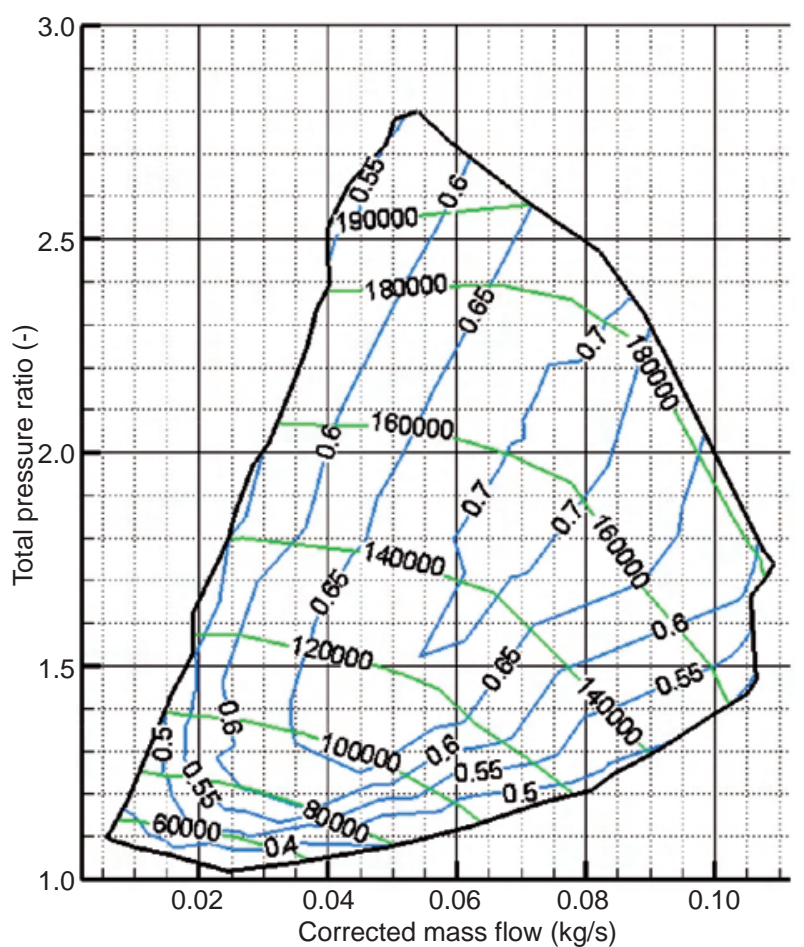

Figure 8

Compressor map with $300^{\circ} \mathrm{C}$ inlet turbine temperature. 


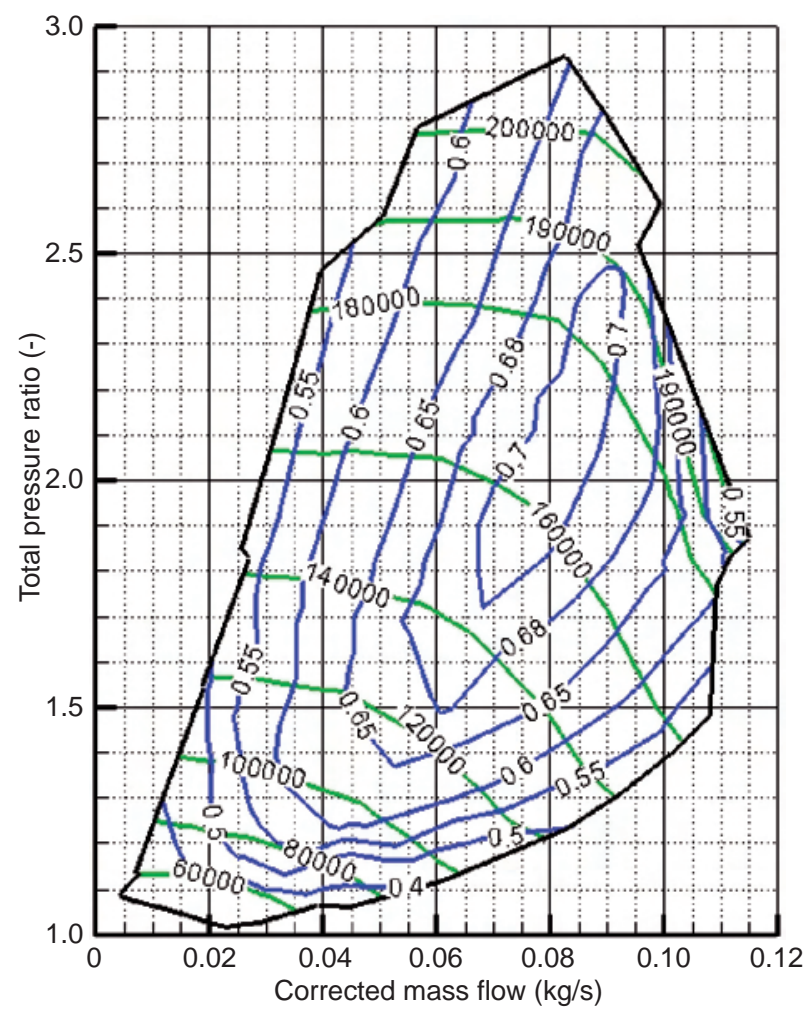

Figure 9

Compressor map with $500^{\circ} \mathrm{C}$ inlet turbine temperature.



Figure 10

Adiabatic (red) and $T_{\text {turbine }}=500^{\circ} \mathrm{C}$ (blue) compressor map comparison.
It is then possible to deduce heat transfer from these various compressor maps.

\subsection{Heat Flux Determination}

Assuming that the heat transfer happens after the impeller (in the diffuser and volute) it is possible to quantify the heat flux transferred from the various maps. Indeed the mechanical power absorbed by the impeller is not affected by heat transfer. It is constant, whatever the inlet turbine temperature:

$$
P_{\text {comp }}=\dot{m} \cdot C p \cdot \frac{T_{c 1}}{\eta_{\text {adia }}}\left(\left(\frac{P_{c 2}}{P_{c 1}}\right)^{\frac{\gamma-1}{\gamma}}-1\right)
$$

First, the efficiency must be calculated along an isospeed line (60 krpm was chosen for this example), for both the adiabatic map and a map measured for a given inlet turbine temperature $\left(500^{\circ} \mathrm{C}\right.$ for this example). This can be done easily with commercial software such as tecplot or matlab. The result, presented in Figure 11, shows the large difference between the two efficiencies.
Then the heat flux transferred can be deduced:

$$
\begin{gathered}
\dot{m} \Delta h_{\text {adia }}=P_{\text {comp }}=\frac{\dot{m} \cdot C p \cdot T_{c 1}}{\eta_{\text {adia }}} \cdot\left(\tau^{\frac{\gamma}{\gamma-1}}-1\right) \\
\dot{m} \Delta h_{500}=P_{c o m p}+Q_{c-500}=\frac{\dot{m} \cdot C p \cdot T_{c 1}}{\eta_{500}} \cdot\left(\tau^{\frac{\gamma}{\gamma-1}}-1\right)
\end{gathered}
$$

then:

$$
Q_{c-500}=\dot{m} \cdot C p \cdot T_{c 1} \cdot\left(\tau^{\frac{\gamma}{\gamma-1}}-1\right)\left(\frac{1}{\eta_{500}}-\frac{1}{\eta_{\text {adia }}}\right)
$$

Figure 12 represents the variation of the heat flux at 300 and $500^{\circ} \mathrm{C}$ compared to compression power for the 50000 , 60000,80000 and $120000 \mathrm{rpm}$ isospeed. These isospeeds correspond respectively to $120.4,144.5,192.7$ and $289 \mathrm{~m} / \mathrm{s}$ blade tip speeds.

It can be seen that the heat flux increase with inlet turbine temperature. For an inlet turbine temperature of $500^{\circ} \mathrm{C}$ heat flux is larger than compression power for $50 \mathrm{krpm}$ isospeed. The error committed when neglecting heat transfer is thus 




Figure 11

- : Adiabatic and $T_{\text {turbine }}=500^{\circ} \mathrm{C}$ compressor efficiency comparison for $60000 \mathrm{rpm}$ isospeed lines (blade tip speed $144.5 \mathrm{~m} / \mathrm{s})$.

very large. The relative importance of heat transfer decreases when rotation speed increases. For $120 \mathrm{krpm}$ isospeed heat flux is only a few percent of compression power. The absolute value of the heat flux also decreases when rotation speed is increased. This can be explained because with higher compression ratio reached at higher rotation speed, the compressor outlet temperatures are higher. Thus the temperature difference between turbine and compressor is reduced, and so is the heat transfer.

\section{COMPRESSOR POWER AND OUTLET TEMPERATURE CALCULATION INCLUDING HEAT TRANSFERS}

In this section, the traditional method is compared to the new method described in this paper which takes the heat transfer into account. For the example it is assumed that the manufacturer compressor map was measured with an inlet turbine temperature of $500^{\circ} \mathrm{C}$ (the turbocharger manufacturer's usually measure the compressor maps at high turbine temperature). The corresponding map is shown in Figure 9. The operating point is defined by a rotation speed of $60 \mathrm{krpm}$ and a corrected mass flow of $0.02 \mathrm{~kg} / \mathrm{s}$ (point A). The efficiency and compression ratio readings are as follows:

- $\eta_{500}=0.4$ and $\tau=1.12$ for the manufacturer map measured with a turbine inlet temperature of $500^{\circ} \mathrm{C}$;

- $\eta_{\text {adia }}=0.65$ and $\tau=1.12$ for the adiabatic map.

With the traditional method, the efficiency provided by the manufacturer is directly used to evaluate the mechanical power absorbed by the compressor, as well as the compressor outlet temperature. Assuming a compressor inlet temperature of $300 \mathrm{~K}$ gives the following results:

$$
T_{c 2}=T_{c 1}+\frac{T_{c 1}}{\eta_{500}}\left(\left(\frac{P_{c 2}}{P_{c 1}}\right)^{\frac{\gamma-1}{\gamma}}-1\right)=324.7 \mathrm{~K}
$$

and Pcomp $=493.6 \mathrm{~W}$.
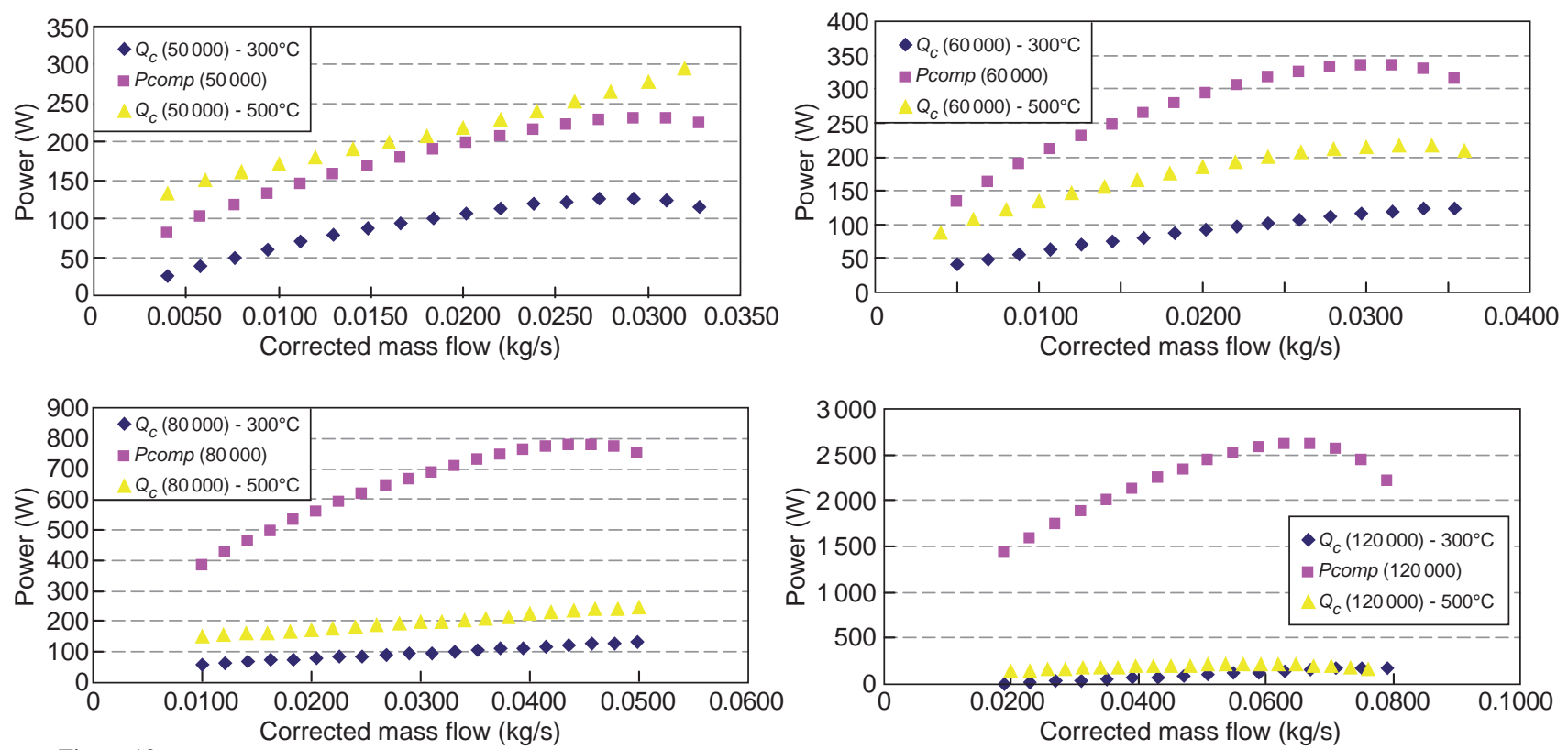

Figure 12

Heat transfer variation for several compressor isospeed lines. 
Obviously, since the compression is supposed to be adiabatic, $\dot{Q}_{c}=0$.

These results do not vary with inlet turbine temperature.

On the other hand, if heat transfers are considered, the inlet turbine temperature does alter the results. The mechanical power absorbed by the compressor is:

$$
\text { Pcomp }=\dot{m} \cdot C p \cdot \frac{T_{c 1}}{\eta_{\text {adia }}}\left(\left(\frac{P_{c 2}}{P_{c 1}}\right)^{\frac{\gamma-1}{\gamma}}-1\right)=303.8 \mathrm{~W}
$$

The first principle of thermodynamics is then applied to calculate the compressor outlet temperature:

$$
\dot{m} \Delta h=\text { Pcomp }+Q_{c}
$$

then:

$$
T_{c 2}=T_{c 1}+\frac{P \operatorname{comp}+Q_{c}}{\dot{m} \cdot C p}
$$

For a very low turbine inlet temperature (around $40^{\circ} \mathrm{C}$ ) for instance the compressor is almost adiabatic. Then $Q_{c}=0$. For inlet turbine temperature $300^{\circ} \mathrm{C}$ and $500^{\circ} \mathrm{C}$, heat fluxes are respectively of $90 \mathrm{~W}$ and $190 \mathrm{~W}$ according to Figure 12 . Corresponding compressor outlet temperatures are gathered in Table 1, assuming a compressor inlet temperature of $27^{\circ} \mathrm{C}$. The experimental outlet temperatures are also included in this table. Obviously, the compressor outlet temperatures calculated with the new method perfectly match the experimental ones, because the heat transfer calculated in the new method are directly based on experimental outlet temperatures.

\section{TABLE 1}

Variation of compressor outlet temperature depending on turbine inlet temperature (point A)

\begin{tabular}{l|c|c|c}
\hline Turbine inlet temperature & $40^{\circ} \mathrm{C}$ & $300^{\circ} \mathrm{C}$ & $500^{\circ} \mathrm{C}$ \\
\hline Compressor outlet temperature (old method) & \multicolumn{3}{|c}{51.7} \\
\hline Compressor outlet temperature (new method) & $42.2^{\circ} \mathrm{C}$ & $46.7^{\circ} \mathrm{C}$ & $51.7^{\circ} \mathrm{C}$ \\
\hline Compressor outlet temperature (experimental) & $42.2^{\circ} \mathrm{C}$ & $46.7^{\circ} \mathrm{C}$ & $51.7^{\circ} \mathrm{C}$ \\
\hline Compressor power old method & \multicolumn{3}{|c}{$493.6 \mathrm{~W}$} \\
\hline Compressor power new method & \multicolumn{3}{|c}{$303.8 \mathrm{~W}$} \\
\hline
\end{tabular}

The old method, however, gives an accurate estimation of compressor outlet temperature when actual inlet turbine temperature is the same as the one used by the manufacturer to establish the compressor map. Otherwise, the discrepancy between old method and experiments can be substantial (over estimation of $9.5^{\circ} \mathrm{C}-$ see Tab. 1).

But the most important point is the discrepancy in the calculation of the mechanical power absorbed by the compressor which reaches $48 \%$ in this example.
The results obtained with an operating point more powered $(\dot{m}=0.05 \mathrm{~kg} / \mathrm{s}$ et $N=120000 \mathrm{tr} / \mathrm{mn}$ ) (point B) are presented in Table 2. For this point, the compression ration is $1.48, \eta_{500}=0.66$ and $\eta_{\text {adia }}=0.72$.

TABLE 2

Variation of compressor outlet temperature depending on turbine inlet temperature (point B)

\begin{tabular}{l|c|c|c}
\hline Turbine inlet temperature & $80^{\circ} \mathrm{C}$ & $300^{\circ} \mathrm{C}$ & $500^{\circ} \mathrm{C}$ \\
\hline Heat transfer & 0 & $109 \mathrm{~W}$ & $224.5 \mathrm{~W}$ \\
\hline Compressor outlet temperature (old method) & \multicolumn{3}{|c}{$81^{\circ} \mathrm{C}$} \\
\hline Compressor outlet temperature (new method) & $76^{\circ} \mathrm{C}$ & $78.4^{\circ} \mathrm{C}$ & $81^{\circ} \mathrm{C}$ \\
\hline Compressor outlet temperature (experimental) & $76^{\circ} \mathrm{C}$ & $78.4^{\circ} \mathrm{C}$ & $81^{\circ} \mathrm{C}$ \\
\hline Compressor power old method & \multicolumn{3}{|c}{$2693.8 \mathrm{~W}$} \\
\hline Compressor power new method & \multicolumn{3}{|c}{$2469.3 \mathrm{~W}$} \\
\hline
\end{tabular}

It can be seen that the difference between the two methods is clearly diminished. The error made considering the compressor is adiabatic is only important for engine low load operating points.

As shown in the paper, one possible way to correctly evaluate the mechanical and thermal power exchanged by the compressor is to measure two different compressor maps: an adiabatic one and then another one corresponding to a high inlet turbine temperature. Since turbocharger test benches allowing such measurements are still rare, numerical simulation could be used to replace some measurements (although it is behind the scope of this paper). Usually the compressor map provided by the manufacturer is measured with a high turbine inlet temperature. A model based on turbocharger dimensions and material characteristics (for compressor, turbine and central housing) and including an evaluation of convective coefficient (for gas on compressor and turbine sides and for lubricating oil) could be used to evaluate the various thermal fluxes depicted in Figure 12. Then an adiabatic map could be deduced, and the new method could be applied.

\section{CONCLUSION}

The experimental results presented in his paper confirm that the automotive turbocharger compressors aren't adiabatic. Indeed, the compressor maps depend on turbine inlet temperature, which shouldn't be the case if no heat transfer occurs. The use of adiabatic model, for example in the engine simulators, generates errors for the compressor power and compressor outlet temperature. The measurement of compressor maps adiabatic and with heat transfer allows to calculate the heat transfer from the turbine to the compressor. This heat flux can be used to correctly evaluate the compressor mechanical power and his outlet temperature. For the tested 
turbocharger, it appears that the difference with the adiabatic method is noticeable only for low rotation speeds, which correspond to engine low load operating points. However, the heat transfer influence certainly depends on the turbocharger size, even if no experimental test was done to verify this point. It is well known that in micro gas turbines for instance, heat transfers are of major importance. The surface to volume ratio is certainly a pertinent parameter to estimate the relative importance of heat transfers.

Finally, in order to precisely quantify the gain over the traditional modelling, a new model with a similar approach should be developed for the turbine. Then, the two new models should be integrated in an engine simulation code.

\section{ACKNOWLEDGMENTS}

The authors thank Renault SA for the financial and material support of this study.

\section{REFERENCES}

1 GT-Power, User's Manual. GT-Suite Version 6.1. Gamma technologies Inc., USA. 2004.

2 AVL, BOOST: thermodynamic cycle calculation, www.avl.com.

3 Wave: 1D engine \& gas dynamics simulation software, www.ricardo.com.
4 AMESim: 1D simulation solution, www.lmsintl.com.

5 Rautenberg M., Mobarak A., Molababic M. (1983) Influence of heat transfer between turbine and compressor on the performance of small turbochargers, JSME Paper 83-Tokyo-IGTC-73, International Gas Turbine Congress.

6 Jung M., Ford R.G., Glover K., Collings N., Christen U., Watts M.J. (2002) Parameterisation and Transient Validation of a Variable Geometry Turbocharger for Mean-Value Modelling at Low and Medium Speed-Load Points, SAE paper 2002-01-2729.

7 Bohn D. (2003) Conjugate Calculation of Flow Field and Heat Transfer in Compressor, Turbine and Casing of a Gas turbine, VGB Powertech. 83, 11, 54-59.

8 Bohn D. (2003) Conjugate Flow and Heat Transfer Investigation of a turbocharger, Part II: Experimental Results, ASME Conference Paper GT2003-38449.

9 Bohn D., Heuer T., Kusterer K. (2005) Conjugate Flow and Heat Transfer Investigation of a Turbo Charger, J. Eng. Gas Turbine. Power 127, 663-669.

10 Riegler C. (1999) Correlations to include heat transfer in gas turbine performance calculations, Aerospace Technology 5, 281-292.

11 Guzovic Z., Matijasevic B., Rusevljan M. (2001) Generalised Correlations for heat transfer determination in turbine cascades, Strojniski Vestnik. 47, 8.

12 Nickel J., Sens M., Grigoriadis P., Pucher H. (2005) Einfluss der Sensorik und der Messstellenanordnung bei der Kennfeldvermessung und im Fahrzeugeinsatz von Turboladern. 10. Aufladetechnische Konferenz 2005, 22-23 september, Dresden.

Final manuscript received inFebruary 2011 Published online in September 2011 